\title{
Building an Innovating Learning Community
}

\author{
Lewis BARKSDALE *1
}

The biggest change in the 57-year history of International College of Technology, Kanazawa, began in 2015 when the school, then called Kanazawa Technical College, began fundamentally redefining its mission. The School System that includes ICT and Kanazawa Institute of Technology proclaimed a vision to educate leaders of innovation for a better world in an integrated course of five years of technical college plus four years of university and graduate research. As a vital part of this plan, ICT redesigned itself as a school for training leaders of global innovation, and began accepting middle school graduates to its new program in 2018.

By "global innovators" we mean professionals who not only possess advanced engineering knowledge and insight, but who are also skilled in finding opportunities to bring about new value with creative solutions, collaborating effectively with experts of diverse fields, and in the context of the global economy with people of diverse cultures and values. As the pace of advance in science and technology accelerates, we believe that the advantages of an advanced level of technical expertise and of experience in research and development in the context of design thinking are greater than ever.

As the first stages of educating such global innovators, ICT provides a fully residential program for the first two years at our new Hakusanroku Campus, followed by a year-long program integrating English, math, science, and engineering at our sister institution, Otago Polytechnic in New Zealand, and finally two years of specialized study at the Kanazawa campus, sharing the advanced fabrication and research facilities of Kanazawa Institute of Technology.

The new program includes the following elements:

1) Early and continuing focus on open-ended projects structured according to Design Thinking principles in an integrated Engineering Design course sequence that spans the five-year curriculum;

2) An emphasis on fostering a spirit of collaborative academic inquiry, honing skills in critical and analytical thinking and in effective communication including discussion and debate;

3) A mission of learning about and contributing to the

Received May 28, 2019

※ 1 President of International College of Technology

Kanazawa local community and natural environment as an overall organizing theme for projects and design experiences, both in general education courses and in engineering courses;

4) Early and gradually-increasing use of English as a medium of instruction, especially in math, science, and engineering courses;

5) A diverse and international school community with ample opportunities to learn to collaborate effectively with people of various nationalities, cultures, and values;

6) Programs to foster creativity and a deep understanding of self, human society, and the world through engagement with humanities and the arts.

In developing the program I called for the faculty to uphold the following shared values:

1) To value collaboration and teamwork as a core methodology in all courses and projects, and as a structure for students, faculty, and staff to build a learning community together.

2) To value broad, multidisciplinary learning and insight in order to understand problems and find opportunities from multiple perspectives.

3) Not to be afraid of risk, but to understand that both innovation and learning require agile, tenacious and intelligent response in a trial and error process. Likewise, to expect and value failure as an inevitable step in our students' learning, problem-solving, research, and design.

4) To value the process of creating knowledge as a fundamental skill for innovative engineering. Students should learn to determine what knowledge they need for a particular project, and how to generate that information through research or experiment. School work should consist in solving problems, creating things or generating a new understanding, not in simply accumulating knowledge.

5) To value the students' intrinsic motivation and strive to strengthen it. Students must be empowered to choose the problems and projects they will work on. Study should feel like play even when it is arduous.

6) While fostering an international outlook, to value the natural environment and society and culture of the Hakusan foothills, where our residential campus is located, as the "home base" of the ICT learning community. To act as responsible stakeholders in the preservation of the natural environment and the revitalization 
and advancement of local region.

As we move into our second year of administering this program, both the challenges and the advantages of what we are attempting have come into clearer focus. We have been fortunate in being able to attract students who are motivated and willing to take on the extra burden of learning skills and content in a foreign language. Still, close cooperation between Japanese and international faculty, and agile teamwork, are important. Approximately two thirds of the faculty in the new Department of Science and Engineering are international, but Japanese faculty are teaching content in English as well.

Teaching techniques that engage the power of active learning are important in any educational program, but are essential where students are being taught in a foreign language.

In any educational endeavor a critical factor is the balance between structure and freedom. Too much structure can dampen motivation; too much freedom can result in loss of purpose. In a program that aims to foster the attitudes and skill sets of innovators, we recognize the value of open-ended design and research projects. As motivated as they are, students in the early years of kosen (technical college) need both to be challenged and to be given the structure and support to help them meet the challenge.

We value diversity, and believe that innovation results from encounters between people of different interests, areas of knowledge, beliefs, and backgrounds. By recruiting both students and faculty from overseas as well as throughout Japan, we hope to build a vibrant community of collaborating researchers and learners. There is potential for interpersonal misunderstandings and clashes. Successful interaction requires excellent communication skills and emotional intelligence.

Our school represents a unique combination of characteristics, perhaps never attempted anywhere before. Building such a learning community is itself innovation. I believe that the faculty and staff of ICT are keenly aware that we are ourselves must learn as we take on this challenge. At least, that is my own stance. 